\title{
A INFLUÊNCIA DA LIGA ACADÊMICA DE TRATAMENTO DE MINÉRIOS NO DESENVOLVIMENTO DOS DISCENTES DO DEPARTAMENTO DE ENG. DE MINAS DA UNIVERSIDADE FEDERAL DE OURO PRETO
}

DOI: 10.37702/2175-957X.COBENGE.2021.3404

Ana Vitória de Moura Gonçalves - anavitoriamoura@gmail.com Universidade Federal de Ouro Preto

Rua Doutor Claudio de Lima 139

35400-000 - Ouro Preto - MG

Vitor Gomes Silva - vitor.gs@aluno.ufop.edu.br

Universidade Federal de Ouro Preto

Rua Cachoeira do Campo 73

35400-000 - Ouro Preto - MG

Samuel Pádua Batista - samuelpaduabatista@hotmail.com

Universidade Federal de Ouro Preto

Praça Barão do Rio Branco 46

35400-000 - Ouro Preto - MG

Pâmela Silva Ferraz - pam_sferraz@hotmail.com

Universidade Federal de Ouro Preto

Rua Paraná 142

35400-000 - Ouro Preto - MG

Miriam Gomes Martins - miriamgmartins1@gmail.com

Universidade Federal de Ouro Preto

Rua Tomás Brandão $127 \mathrm{~A}$

35400-000 - OURO PRETO - MG

Clarisse Barbosa de Oliveira - clarissebarbosa2@gmail.com

Universidade Federal de Ouro Preto

Rua José Moreira Júnior 383

35400-000 - Ouro Preto - MG

Vitor Moreira Cangussu - vitor.cangussu10@gmail.com

Universidade Federal de Ouro Preto 
Rua Alfa 331

35400-000 - Ouro Preto - MG

Isabella Martins de Souza Vieira - isamsvieira@gmail.com

Universidade Federal de Ouro Preto

Rua José Trindade 61

35400-000 - Ouro Preto - MG

Paulo Henrique Liberato da Silva - paulo.liberato@aluno.ufop.edu.br

Universidade Federal de Ouro Preto

Rua Arthur Versiani Machado 590

35400-000 - Ouro Preto - MG

Danillo Fernando Andrade da Silva - danillofernando@outlook.com

Universidade Federal de Ouro Preto

Rua Um 232

35047-010 - Governador Valadares - MG

Lucas Henrique Gonçalves Ruocco - lucasruocco@hotmail.com

Universidade Federal de Ouro Preto

Rua Professor Paulo Magalhães Gomes 379

35400-000 - Ouro Preto - MG

Vladmir Kronemberger Alves - vladmir.alves2ufop.edu.br

Universidade Federal de Ouro Preto

Campus Universitário sem número

35400-000 - Ouro Preto - MG

Resumo: Este trabalho tem a finalidade de apresentar a estrutura e a atuação da Liga Acadêmica de Tratamento de Minérios (LATRAM) da Universidade Federal de Ouro Preto (UFOP). Uma pesquisa foi realizada com os discentes do curso de Engenharia de Minas da UFOP, independente de já terem sido membros ou não, para que pudessem apontar em que a LATRAM contribuiu para sua formação acadêmica na área de tratamento de minérios. A partir dessa pesquisa, observou-se grande influência da Liga em relação aos alunos e foi possível obter sugestões de melhorias.

Palavras-chave: Liga Acadêmica; Mineração; Educação; Extensão. 


\section{INTRODUÇÃO}

As atividades mineradoras têm um papel fundamental na evolução da humanidade e sua influência no cotidiano aumenta cada vez mais de acordo com o desenvolvimento do mundo. A maioria dos bens minerais existentes na superfície terrestre necessita, para a sua utilização, de algum tratamento ou beneficiamento para selecionar as suas propriedades físicas e/ou químicas de interesse (LUZ; LINS, 2018). Tal seleção se dá através do conjunto de operações que modifica a granulometria, concentração e forma das espécies minerais (LUZ; SAMPAIO; FRANÇA, 2010). A indústria da mineração é, portanto, indispensável à sociedade.

A Universidade Federal de Ouro Preto, através dos cursos de Engenharia de Minas e Metalúrgica dispõe de disciplinas voltadas ao beneficiamento mineral. Visando principalmente complementar o aprendizado adquirido em sala de aula, correlacionar os conhecimentos com a prática e fomentar o interesse em pesquisa, criou-se a Liga Acadêmica de Tratamento de Minérios, LATRAM.

Ligas Acadêmicas são entidades de caráter multidisciplinar, sem fins lucrativos, políticos ou religiosos, de duração ilimitada, organizadas por discentes universitários, sob a supervisão de profissionais, doutores e professores vinculados à universidade. (COSTA et al., 2009). Criado em 1920, o movimento das ligas acadêmicas surgiu no âmbito da medicina, em São Paulo, e vêm cada vez mais ganhando força no cenário universitário em muitos cursos. Além de possibilitar a potencialização na formação dos acadêmicos e proporcionar uma reflexão a respeito do crescimento pessoal, as ligas acadêmicas são criadoras de oportunidades de desenvolvimento de trabalhos científicos, projetos culturais e sociais, entre outros (SILVA et al., 2018).

Portanto, em 2014, foi criada a LATRAM, liga pioneira no estudo do tratamento de minérios, a qual tem por objetivo congregar, estimular e auxiliar estudantes dos cursos de Engenharia de Minas e Metalúrgica interessados no estudo, pesquisa e extensão. Esse artigo busca apresentar a estrutura e as atividades desenvolvidas pela Liga, tais como reuniões científicas entre membros, organização e promoção de eventos de caráter científico, abertos à comunidade acadêmica, e realização de projetos de cunho social. Além disso, será apresentada uma pesquisa realizada com os discentes do curso de Engenharia de Minas e os ex-membros da LATRAM, sobre a visibilidade da entidade no departamento e sua contribuição no desenvolvimento pessoal.

\section{SOBRE A LATRAM}

A LATRAM é uma das entidades estudantis do Departamento de Engenharia de Minas (DEMIN). De acordo com seu estatuto, pode ser composta por, no máximo, 15 membros. A Liga é constituída por um único órgão executivo, denominado Diretoria, composto por seis integrantes: Diretor Presidente, Vice-Presidente, Tesoureiro, Diretor Científico, Diretor de Comunicação e Diretor de Extensão. Os demais ligantes são alocados como assessores dos diretores Científico, de Extensão e de Comunicação. Cada membro da Diretoria tem atribuições específicas, apresentadas a seguir.

\subsection{Diretor-Presidente}

O Diretor-Presidente é o representante da Liga tanto internamente, como perante a outros órgãos, instituições e comunidade. É responsável por planejar, coordenar e supervisionar todas as atividades realizadas pela Liga junto à Diretoria, levantar discussões acerca do funcionamento da LATRAM, além de fazer cumprir as normas do seu Estatuto. 
Outras de suas atribuições são: confeccionar atas, declarações e certificados, gerenciar o processo seletivo e o processo de eleição da nova Diretoria.

\subsection{Vice-Presidente}

O Vice-Presidente tem como atribuições controlar a frequência dos demais membros, redigir documentos oficiais e extraoficiais, registrar atas e criar formulários para avaliar a participação dos ligantes, cujos resultados poderão ser utilizados para promover melhorias nas atividades da Liga. Ainda, o Vice-Presidente é responsável por auxiliar o Diretor Presidente quando necessário e, em caso de ausência ou impedimento deste, secretariar as Reuniões Científicas e Assembleias Gerais.

\subsection{Tesoureiro}

O Tesoureiro tem por função controlar a arrecadação de valores obtidos em inscrições de cursos, simpósios e demais eventos realizados pela Liga, além de coordenar a aplicação de tais recursos em prol da própria entidade. Com a obrigação de divulgar periodicamente um extrato com as movimentações financeiras aos membros e à Diretoria. Quando em situações de impedimento ou ausência do Vice-Presidente, o Tesoureiro o substitui no ambiente da liga acadêmica.

\subsection{Diretor Científico}

O Diretor Científico tem por dever fomentar a produção científica da Liga, incentivando a realização de pesquisas através da escolha de materiais relacionados à área de tratamento de minérios. Junto a seus assessores, ele realiza a seleção de temas a serem debatidos nas reuniões ou em palestras ministradas à comunidade acadêmica da Escola de Minas. Além disso, é de sua responsabilidade a busca por eventos técnicos e/ou científicos dos quais a Liga possa participar.

\subsection{Diretor de Comunicação}

O Diretor de Comunicação, juntamente aos seus assessores, tem por função criar, padronizar e zelar pela identidade visual da LATRAM. É de sua responsabilidade promover a comunicação entre os membros, além de integrar e informar a comunidade acadêmica da universidade sobre ações da Liga e seu Processo Seletivo, através do gerenciamento das mídias sociais.

\subsection{Diretor de Extensão}

O Diretor de Extensão tem como responsabilidade criar e promover projetos que alcancem a comunidade de Ouro Preto e região. Tais projetos têm diferentes finalidades, atuando de forma solidária, por meio de campanhas sociais e no âmbito acadêmico, difundindo o conhecimento acerca do tratamento de minérios. Ademais, o diretor é responsável por acompanhar as atividades de extensão e elaborar relatórios desses projetos para que sejam apresentados em reuniões administrativas.

\section{ATIVIDADES DA LIGA}

\subsection{Reuniões Administrativas}

As Reuniões Administrativas ocorrem em média 2 (duas) vezes por mês, tendo como participantes os membros da Liga. Seu objetivo é promover o diálogo acerca da programação e organização das atividades de cada diretor e respectivos assessores. 


\subsection{Assembleia Geral}

A Assembleia Geral pode ter caráter ordinário ou extraordinário. A ordinária ocorre no início e no final de cada semestre, tendo como objetivo discutir o planejamento semestral da Liga. Em geral, as principais pautas são eleger novos membros que deverão assumir os cargos de Diretoria, além de modificar e aprovar alterações no estatuto. A qualquer momento em que houver a necessidade de discutir assuntos de relativa urgência, é convocada a Assembleia Geral Extraordinária.

\section{Processo seletivo}

O Processo Seletivo é aberto conforme a necessidade de substituição de membros que tenham se desligado. Geralmente, a seleção se baseia na análise de atestado de matrícula, currículo e texto relacionado ao tratamento de minérios, além da realização de apresentação oral e entrevista com os candidatos. Os interessados em ingressar na Liga devem cursar Engenharia de Minas ou Metalúrgica entre o segundo e oitavo período.

\subsection{Atividades junto à outras entidades}

No âmbito da extensão, a Liga desenvolveu ações beneficentes (apresentadas no item 3.6) junto à Minera Jr. e o CREA Jr. Núcleo Ouro Preto. Na área de ensino, em parceria com a Orientação Acadêmica da Engenharia de Minas (OAEM), os ligantes apresentam a LATRAM e os laboratórios de tratamento de minérios aos calouros do curso de Engenharia de Minas.

\subsection{Reuniões Científicas}

As reuniões científicas são encontros semanais, os quais consistem em um debate sobre determinado tópico que esteja diretamente relacionado à mineração e ao tratamento de minérios. O Diretor Científico é encarregado de propor uma base de dados para estudo, a qual é composta, geralmente, por produções científicas na forma de artigos, livros, vídeos etc. Esse material é disponibilizado com antecedência aos demais ligantes para ser analisado e discutido durante as reuniões, de forma que haja um compartilhamento de conhecimento entre os participantes.

\subsection{Projetos de extensão}

Uma diretriz fundamental da Liga é estar em contato com a sociedade, possibilitando uma troca de experiências entre os membros da LATRAM e o público, para além da universidade. Para tanto, são realizadas ações que visam promover conhecimento e praticar a filantropia. Buscando integrar diferentes ramos da comunidade, cada atividade tem segmentos distintos e objetivos específicos, os quais serão apresentados abaixo.

\section{Campanhas filantrópicas}

A Campanha do Agasalho, realizada em conjunto com o CREA Jr. Núcleo Ouro Preto e Minera Jr., é um projeto desenvolvido durante o inverno que tem como propósito arrecadar agasalhos e cobertores e destiná-los a instituições que prestam assistência a comunidade ouro-pretana. Já o Natal Solidário, com início em 2018, é um projeto o qual tem por objetivo a arrecadação de alimentos e produtos de primeira necessidade, destinados às famílias carentes de Ouro Preto.

\section{Mineração para Escolas}

O projeto intitulado "Mineração para Escolas" é voltado às escolas de Ouro Preto e Mariana, e tem como objetivo promover às crianças, jovens e professores do ensino infantil, 
fundamental e médio, o entendimento das diferentes fases do ciclo da mineração, bem como a importância desse setor na atualidade.

O projeto foi executado nos anos de 2015, 2017 e 2018. Em 2015, o projeto tinha como público-alvo crianças, jovens e professores das escolas de Ouro Preto e seu objetivo era apresentar as fases da mineração, juntamente com a importância de cada uma para a região. Em 2017, o projeto continuou sendo realizado nas escolas de Ouro Preto, para os ensinos infantil, fundamental e médio. Neste ano, o principal objetivo era demonstrar a inserção da mineração nos materiais utilizados no cotidiano e instigar o interesse dos alunos pela área. E, em 2018, o projeto se expandiu, sendo realizado em Mariana, desenvolvendo atividades ligadas à mineração e, também, ressaltando a importância da mineração nos materiais usados no cotidiano. título deve ser digitado em negrito, em letras maiúsculas, em fonte Arial tamanho 14.pt, com alinhamento centralizado, não devendo exceder três (3) linhas. Deixe três (3) linhas de espaço (12 pt) entre o final do título e o resumo.

\section{Mostra de Profissões}

A Mostra de Profissões da UFOP acontece anualmente e tem como objetivo apresentar os cursos da Universidade à comunidade. As entidades estudantis do DEMIN participam representando e apresentando o curso de Engenharia de Minas. A LATRAM realiza apresentações didáticas e interativas visando cumprir seu papel: despertar o interesse dos visitantes acerca da mineração e, principalmente, do tratamento de minérios.

\section{RESULTADOS}

A LATRAM tem a função de desenvolver habilidades dos integrantes, estimular o interesse dos alunos pela área de atuação e ampliar o conhecimento sobre Tratamento de Minérios através da leitura de artigos científicos, apresentação de palestras e realização de trabalhos acadêmicos. Além da capacitação técnica, a Liga propõe trabalhos de extensão voltados para a comunidade regional e universitária. Com o intuito de avaliar suas atividades, a LATRAM aplicou dois questionários, um destinado aos alunos do departamento e outro aos ex-membros, disponibilizados de agosto a outubro de 2020, dos quais foram obtidas respostas de 89 (oitenta e nove) pessoas. Os resultados serão discutidos abaixo.

\subsection{Pesquisa realizada com foco nos alunos do Departamento de Engenharia de Minas}

\section{Conhecimento sobre ligas acadêmicas}

Embora as ligas acadêmicas não sejam tão difundidas no âmbito dos cursos de engenharia, em comparação com os da saúde, obteve-se resultados satisfatórios em relação ao conhecimento sobre o que de fato é uma liga acadêmica. Dentre as respostas obtidas do questionário aplicado aos alunos do departamento, 89,7\% apresentaram conhecimento prévio sobre ligas acadêmicas e 93,6\% afirmam ter conhecimento sobre as atividades da LATRAM. Apesar dos valores se mostrarem consideravelmente altos, notase que o conhecimento dos alunos sobre as atividades da LATRAM é maior do que o conhecimento geral sobre ligas acadêmicas. Tais resultados se deram em decorrência do positivo trabalho de divulgação sobre a própria entidade, através da realização de eventos, disposição de cartazes na universidade, divulgação da Liga nas salas de aula, redes sociais, indicação por amigos, entre outros. Essas informações também foram coletadas, através do formulário, em que os alunos poderiam escolher mais de uma opção sobre como 
conheceram o trabalho da LATRAM. Dentre os resultados, destaca-se que o meio de divulgação mais efetivo é a indicação por amigos, que obteve 40 (quarenta) das respostas, como demonstrado na Figura 1.

Figura 1 - Redes de divulgação.

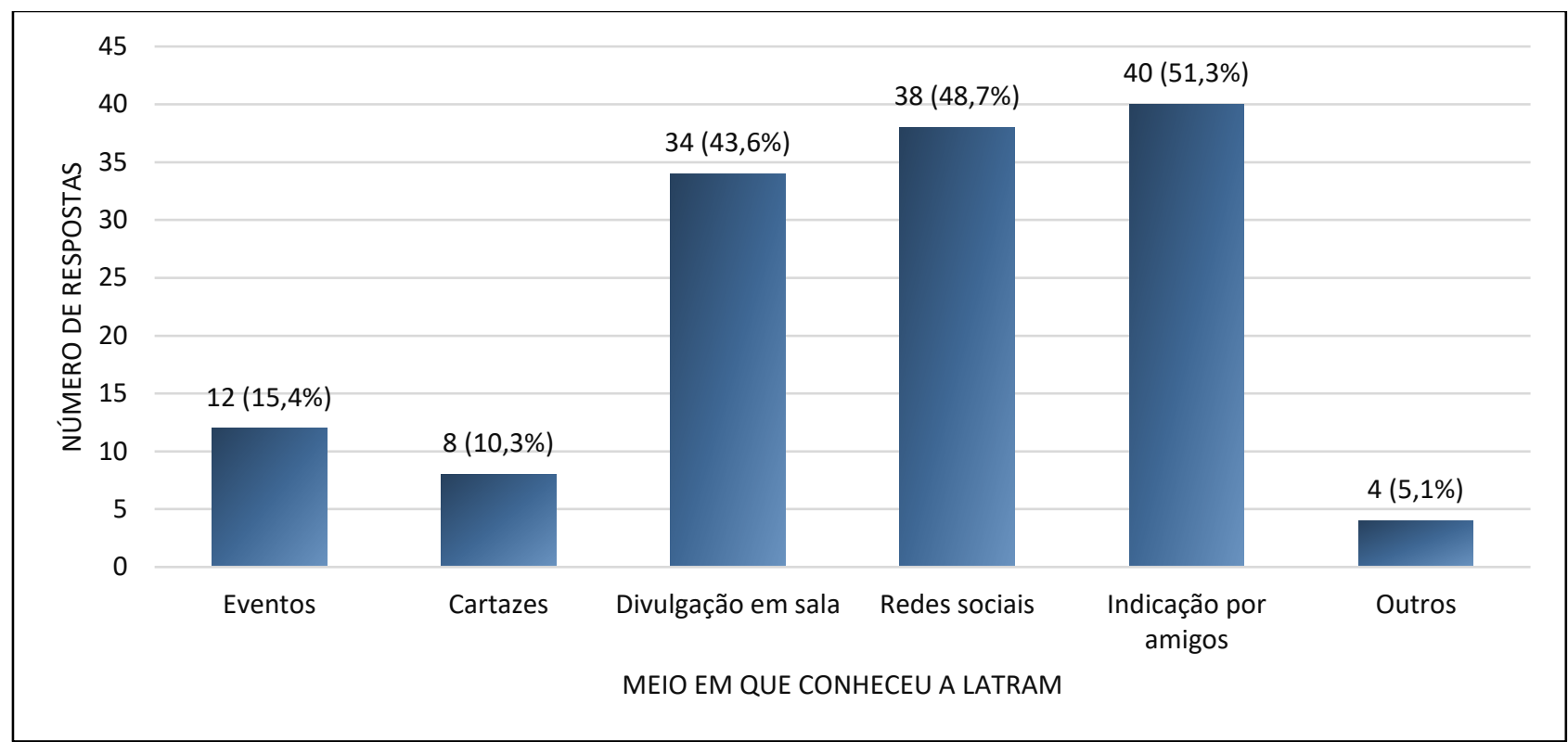

Fonte: Elaborado pelos autores. 


\section{Primeiro contato com tratamento de minérios}

De acordo com a pesquisa, somente $15,6 \%$ dos alunos participantes tiveram seu primeiro contato com o tratamento de minérios através da LATRAM, em sua parceria com a OAEM. Apesar disso, esta atividade foi bem avaliada, mostrando a sua importância para os calouros do curso. A ação recebeu nota máxima de $50 \%$ dos entrevistados, enquanto os outros $50 \%$ também conferiram notas elevadas à ação, como mostra a Figura 2.

Figura 2: Avaliação de visita ao Laboratório de Tratamento de Minérios.

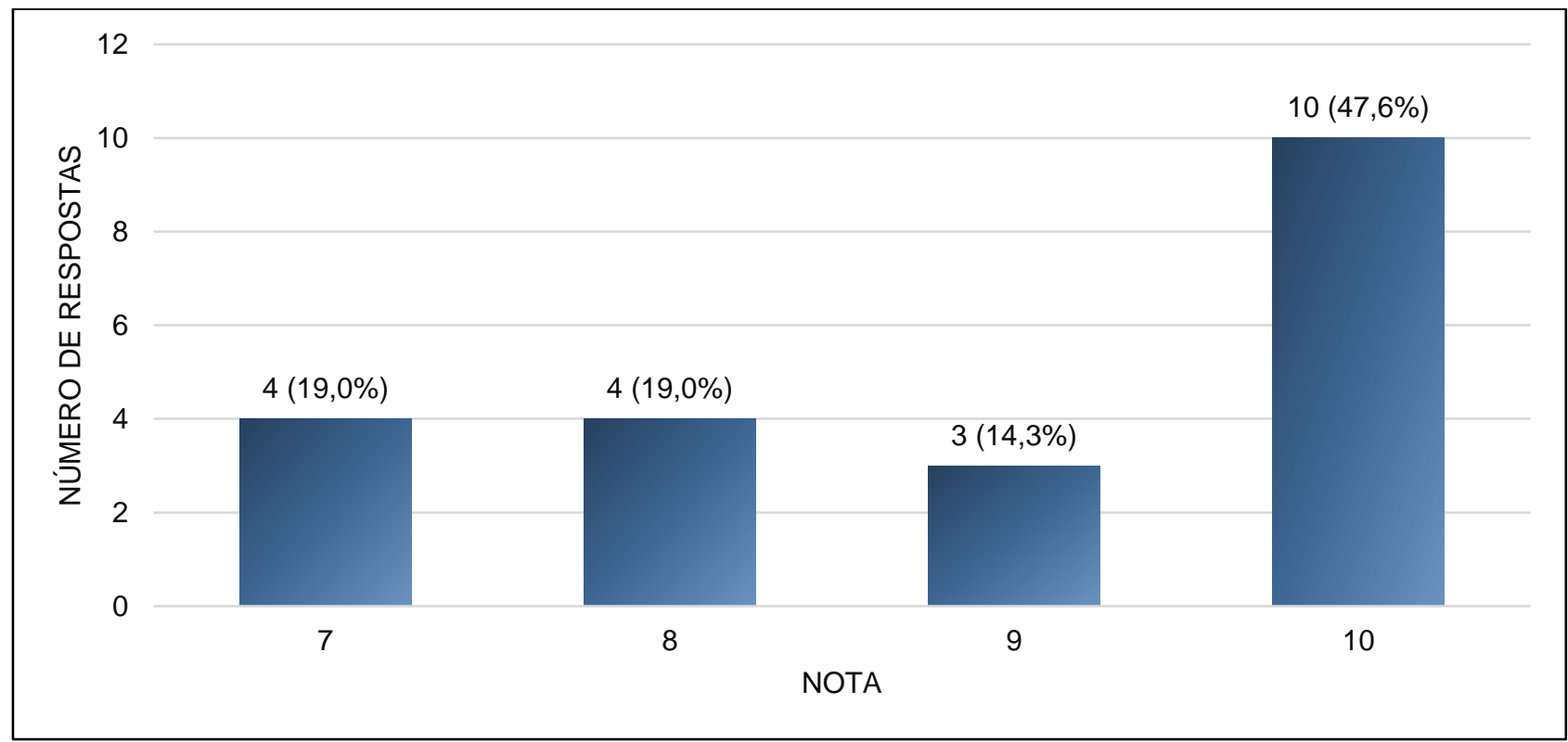

Fonte: Elaborado pelos autores.

\section{Projetos de destaque}

Dentre os projetos da Liga, os que receberam maior destaque por parte dos participantes da pesquisa foram a apresentação da LATRAM para os calouros $(71,8 \%)$ e a apresentação do laboratório de tratamento de minérios $(55,1 \%)$. Pelo fato de serem projetos voltados para calouros, esses são os mais conhecidos pelos alunos, uma vez que a participação deles é reforçada pela parceria com a OAEM. Outros projetos, que devem ser mencionados por sua importância social são a Campanha do Agasalho $(55,1 \%)$ e o Natal Solidário (30,1\%). O projeto Mineração para Escolas é o menos conhecido pelos alunos $(21,8 \%)$, provavelmente pelo fato de ter sido realizado fora da universidade. A compilação dos resultados pode ser vista na Figura 3, a seguir. 
Figura 3: Projetos conhecidos. Acho melhor colocar um número para cada tópico e apresentar uma legenda no gráfico para melhorar a visualização.)

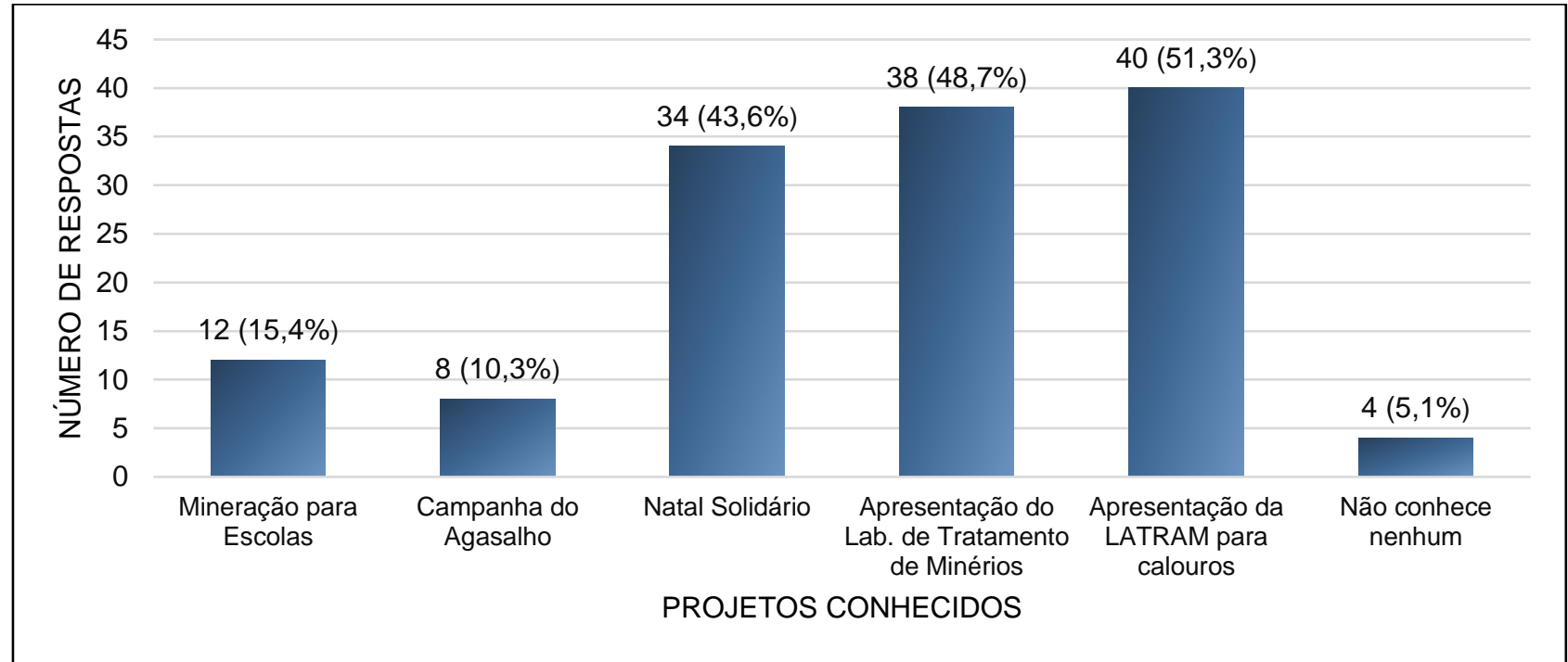

Fonte: Elaborado pelos autores.

\section{Expansão das atividades}

Com base nos resultados dos questionários e visando se fazer mais presente no cotidiano dos discentes e da comunidade, além de promover os conhecimentos relacionados à mineração e ao tratamento de minérios, a LATRAM pretende expandir e diversificar suas atividades e projetos.

É prevista a criação de um evento que reunirá trabalhos científicos produzidos por discentes da graduação e da pós-graduação, de temática relacionada ao tratamento de minérios, denominado Simpósio de Tratamento de Minérios. Além disso, a Liga se propõe a oferecer palestras que abordarão temas relevantes e atuais. Elas serão abertas à comunidade acadêmica e poderão ocorrer no início dos semestres letivos, em um evento denominado Aula Inaugural ou, ainda, ao longo dos semestres letivos, em um evento denominado Café Tratamentista.

Ainda, é planejada a abertura de edições específicas das reuniões científicas ao público. Tais reuniões serão divulgadas com antecedência e será fornecido um formulário on-line para que os interessados se inscrevam. Ademais, serão promovidos cursos de qualificação a serem planejados pelos ligantes, com o propósito de incentivar e colaborar para o desenvolvimento de habilidades essenciais para a formação pessoal e profissional dos discentes. Por fim, é prevista a criação de um novo projeto de extensão, que sucederá o Mineração para Escolas e terá a finalidade de trabalhar em conjunto com a comunidade ouro-pretana e conscientizá-la sobre o papel e a importância da mineração.

\subsection{Pesquisa realizada com foco nos ligantes egressos}

\section{Habilidades desenvolvidas}

Os resultados da pesquisa mostram que a participação na LATRAM auxiliou os ligantes egressos ao cursarem disciplinas relacionadas ao tratamento de minérios (Figura 4) bem como no desenvolvimento de habilidades pessoais e profissionais (Figura 5), tais como: falar em público, leitura regular, oratória, pesquisas regulares, trabalhar em grupo, saber ouvir, dedicação, proatividade e liderança. 
Figura 4: Porcentagem de pessoas cujos conhecimentos adquiridos na Liga auxiliaram ao cursar disciplinas relacionadas ao tratamento de minérios.

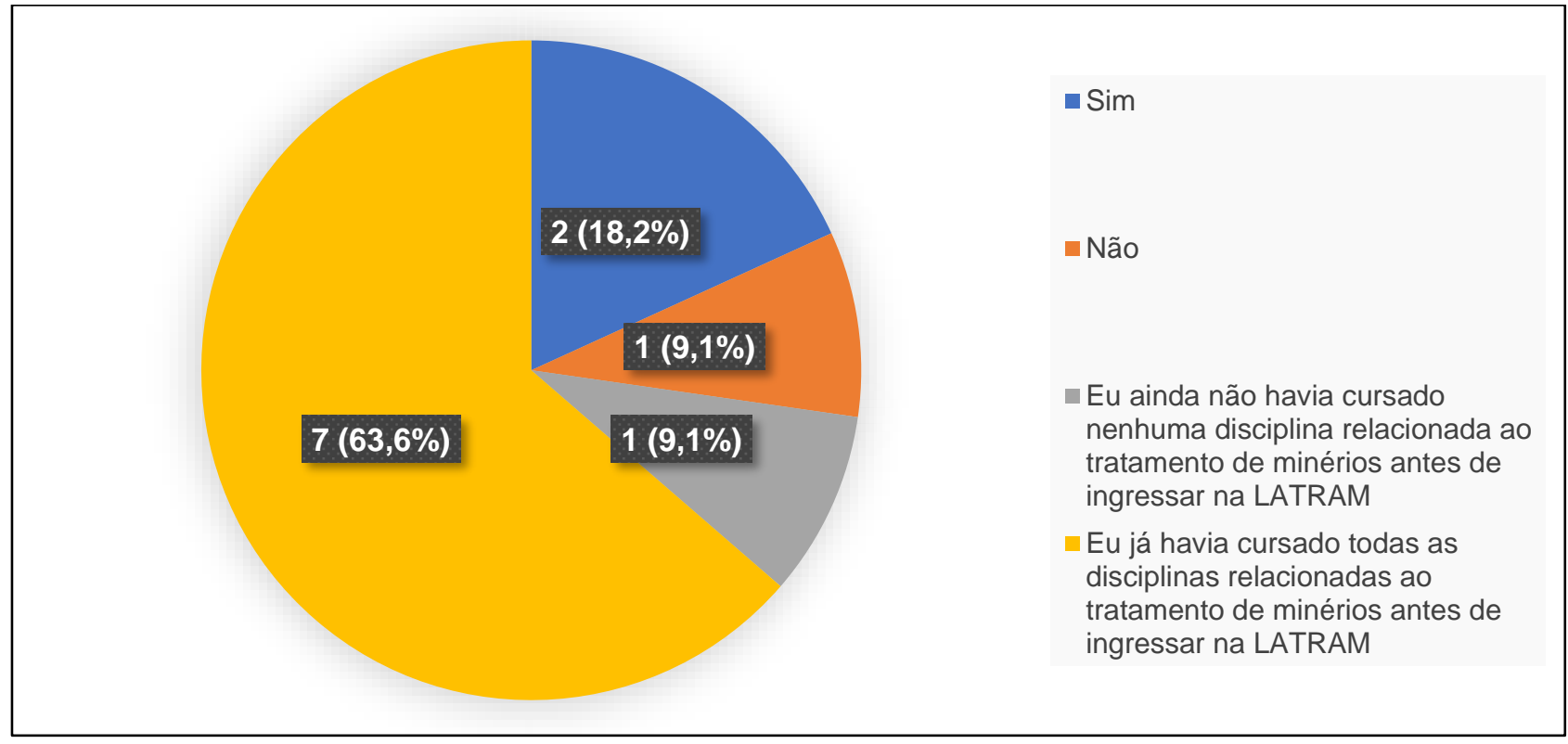

Fonte: Elaborado pelos autores.

Figura 5: Habilidades desenvolvidas

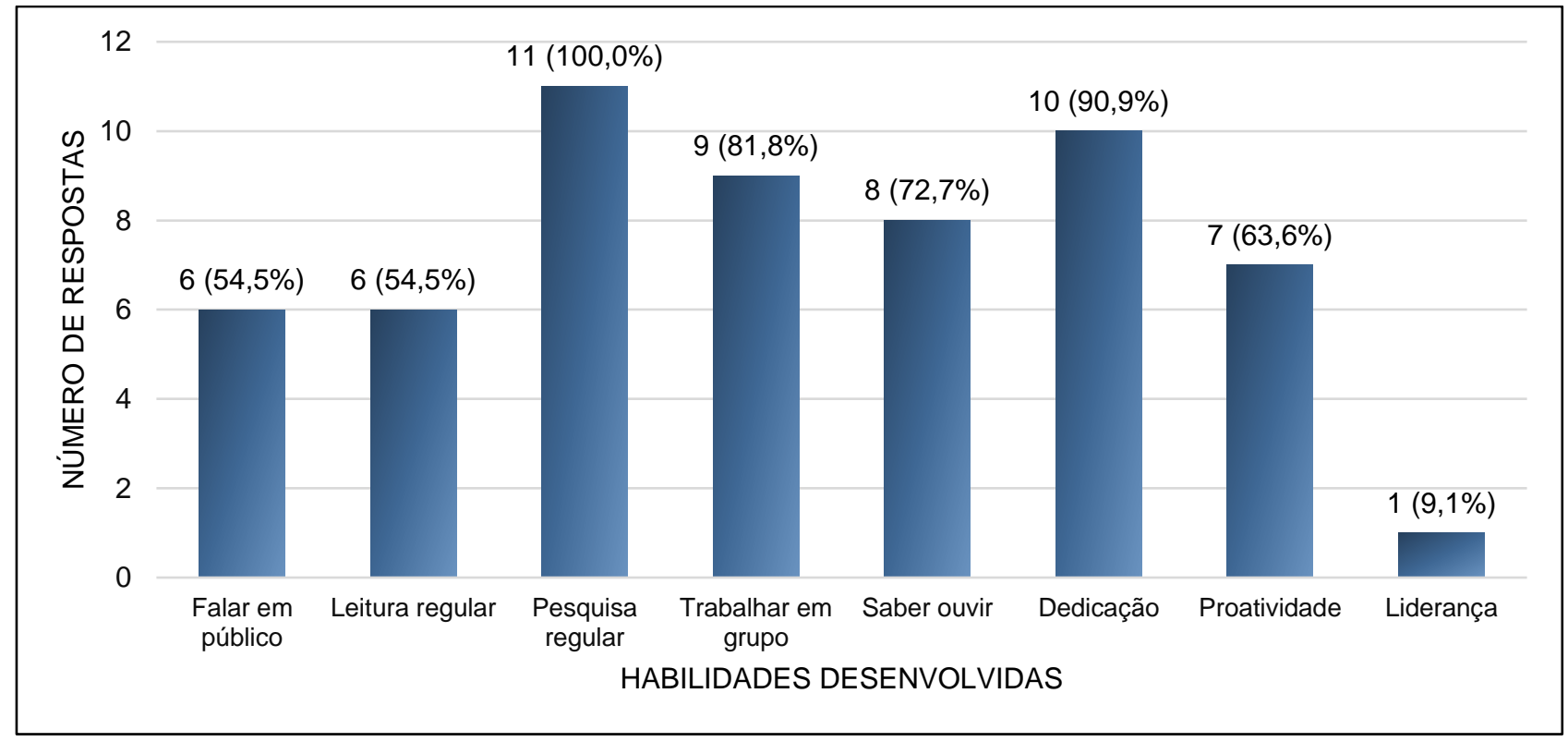

Fonte: Elaborado pelos autores.

Dentre os ligantes egressos participantes da pesquisa e que já concluíram a graduação, nenhum deles atua na área de tratamento de minérios e, para $66 \%$ destes, a LATRAM não influenciou na escolha de sua área de atuação. Entretanto, a participação na Liga abriu possibilidades de ter contato com professores da área e com outros colegas de curso durante a graduação, além de agregar no entendimento de processos e no trabalho em equipe. 


\section{CONSIDERAÇÕES FINAIS}

Este artigo buscou abordar o conceito, história e objetivo das ligas acadêmicas em geral, e apresentar a LATRAM, identificando seu modelo de gestão, baseado nas divisões de tarefas dos membros, por grupos de atuação. As atividades básicas desenvolvidas pela Liga têm como foco incentivar o estudo em Tratamento de Minérios e desenvolver habilidade de gestão através da coordenação das tarefas da entidade. Além do interesse técnico, outra linha de atuação são os projetos de extensão, os quais têm por objetivo aproximar a Liga da comunidade ouro-pretana, divulgando conhecimentos sobre a Mineração e sua importância, além de cumprir o papel social através da organização de campanhas de doação de agasalho e mantimentos.

Com o propósito de avaliar a influência da Liga sobre os alunos do departamento e ex-membros, além de buscar um feedback a respeito das atividades desenvolvidas, aplicou-se questionários para uma coleta de dados. A partir dos resultados foi possível concluir que a LATRAM desempenha um papel importante no departamento, visto que mais de $90 \%$ dos alunos de Engenharia de Minas têm conhecimento prévio sobre a Liga. Pôdese concluir também que a parceria com a OAEM, a qual proporciona aos calouros uma visita ao laboratório de tratamento de minério, possui uma visibilidade bem positiva, pois recebeu notas máximas de $50 \%$ dos alunos e acima de 7 dos outros $50 \%$.

Em relação aos ex-membros, a Liga auxiliou na compreensão de temas técnicos, incentivou a leitura e a realização de pesquisas acadêmicas, além disso, as habilidades desenvolvidas como trabalho em grupo e proatividade, se sobressaíram nos resultados. Dessa forma, a pesquisa foi de extrema importância para o crescimento da LATRAM e os resultados serão utilizados para aperfeiçoar as atividades e projetos já realizados, além de desenvolver melhorias, contribuindo assim, com a evolução da liga e dos alunos de Engenharia de Minas e Metalurgia da UFOP.

\section{REFERÊNCIAS}

COSTA, Alana Parreira.; AFONSO, Cristina Lopes; DEMUNER, Juliana Matias Marra; PIRES, Wynna Chrislaine. A importância da Liga Acadêmica de Queimaduras. Revista Brasileira de Queimaduras, Goiânia, v.8, n.3, p. 101-105, 2009.

LUZ, Adão Benvindo da; LINS, Fernando Antonio Freitas. Introdução ao Tratamento de Minérios. In: LUZ, Adão Benvindo; SAMPAIO, João Alves; FRANÇA, Silvia Cistina Alves. Tratamento de Minérios. 5. ed. Rio de Janeiro: Ed. CETEM/MCTI, 2010. p. 3.

LUZ, Adão Benvindo da; LINS, Fernando Antonio Freitas. Introdução ao Tratamento de Minérios. In: LUZ, Adão Benvindo; SAMPAIO, João Alves; FRANÇA, Silvia Cistina Alves. Tratamento de Minérios. 6. ed. Rio de Janeiro: Ed. CETEM/MCTI, 2018. p. 3.

SILVA, Davi Porfirio et al. Proposição, fundação, implantação e consolidação de uma Liga Acadêmica. Revista de Enfermagem, Recife, p. 1486-1492, mai/2018. Disponível em: http://rbqueimaduras.org.br/export-pdf/21/v8n3a06.pdf. Acesso em: 06 ago. 2020. 
THE INFLUENCE OF THE ACADEMIC LEAGUE OF MINERAL PROCESSING IN THE DEVELOPMENT OF THE STUDENTS OF THE MINING ENGINEERING DEPARTMENT OF THE FEDERAL UNIVERSITY OF OURO PRETO - COBENGE 2021

\begin{abstract}
The purpose of this paper is to present the structure and activities of the Academic League of Mineral Processing (LATRAM) of the Federal University of Ouro Preto (UFOP). A survey was conducted among students in UFOP's Mining Engineering course, whether or not they had already been members, so that they could point out how LATRAM had contributed to their academic education in the area of mineral processing. Based on this survey, a great influence of the League was observed in regard to the students and it was possible to obtain suggestions for improvements.
\end{abstract}

Keywords: Academic League; Mining; Education; Extension. 